\title{
Antibiotic resistance assessment in $S$. aureus strains isolated from raw sheep's milk cheese
}

\author{
V. Spanu • S. Virdis - C. Scarano $\cdot$ F. Cossu • \\ E. P. L. De Santis • A. M. Cosseddu
}

Published online: 2 May 2010

(C) Springer Science+Business Media B.V. 2010

\begin{abstract}
In vitro activities of 16 antibiotics were tested against 36 Staphylococcus aureus $(S A)$ strains isolated from raw sheep's milk cheese from six dairies. The minimum inhibitory concentration (MIC) was determined using a broth microdilution method (CLSI). All 36 isolates were analyzed for the presence of the accessory gene regulator gene, agr (I-IV), and genes encoding resistance to methicillin (mecA), erythromycin ( $\mathrm{rm} A)$, penicillin (blaZ), and vancomycin $(\operatorname{van} A-B)$. The isolates were also analyzed for similarities in pulsed-field gel electrophoresis (PFGE) patterns. $S A$ strains showed resistance to ampicillin (36.1\%), penicillin (33.3\%), tetracycline (11.1\%), and cloxacillin $(2.8 \%)$ but were susceptible $(\geq 94.4 \%)$ to 12 out of 16 tested antimicrobials. The overall susceptibility of the strains to oxacillin, vancomycin, and erythromycin was confirmed by the absence of the mecA, van $A-B$, and erm $A$ genes. The PFGE results showed that 32 strains belonged to 10 different clusters (P1-P10) while four strains were untypeable.
\end{abstract}

Keywords $S$. aureus $\cdot$ Sheep cheese $\cdot$ Antibiotic resistance $\cdot$ MIC $\cdot$ Genes

$\begin{array}{ll}\text { Abbreviations } \\ \text { SA } & \text { Staphylococcus aureus } \\ \text { MIC } & \text { minimum inhibitory concentration } \\ \text { AMR } & \text { antimicrobial resistance } \\ \text { MRSA } & \text { methicillin-resistant Staphylococcus aureus } \\ \text { PFGE } & \text { pulsed-field gel electrophoresis } \\ \text { CPS } & \text { coagulase-positive staphylococci }\end{array}$

\section{Introduction}

$S$. aureus $(S A)$ is involved in food poisoning outbreaks and systemic human diseases. Antibiotic resistance in $S A$ isolated from food of animal origins has been reported. The

V. Spanu $(\bowtie) \cdot$ S. Virdis $\cdot$ C. Scarano $\cdot$ F. Cossu $\cdot$ E. P. L. De Santis $\cdot$ A. M. Cosseddu Dipartimento di Biologia Animale, Facoltà di Medicina Veterinaria, Sassari, Italy e-mail: vspanu@uniss.it 
European Food Safety Authority (EFSA) has identified animals as a possible reservoir of $S A$ antimicrobial-resistant (AMR) strains. Transmission through foods of AMR strains involved in human outbreaks has been reported in sporadic cases (EFSA 2008). Several mechanisms are involved in the antibiotic resistance of $S A$. Plasmid-encoded $\beta$-lactamase inactivates penicillin. Methicillin and other semi-synthetic penicillins have been effective against $\beta$-lactamase producer bacterial strains. However, the emergence of methicillinresistant $S A$ (MRSA) strains have been reported. MRSA strains harbor the mecA gene, which encodes a low-affinity penicillin-binding protein (PBP2a). Nosocomial infections caused by MRSA can sometimes lead to death (Moreillon and Que 2004). Macrolide resistance in $S A$ can be caused by a target modification of a $23 \mathrm{~S}$ rRNA methylase, encoded by the erm genes. $S A$ can also be resistant to vancomycin, which has been used successfully to treat MRSA strains. Vancomycin resistance is encoded by several genes and appears to have originated from mutations under antibiotic-selective pressure. Antibiotic resistance is frequently acquired by exchange of mobile DNA elements during food processing between pathogenic and non-pathogenic microorganisms. In the dairy sheep industry, $S A$ AMR strains can be recovered from raw milk, secretions from animals with mastitis, and dairy products. The aim of the present study was to assess a protocol to characterize $S A$ isolates and their resistance to antibiotics using phenotypic and molecular techniques. In $S A$ strains isolated from raw sheep's milk cheese collected at early stages of the cheese making process, minimum inhibitory concentrations (MICs) and susceptibility to antibiotics used in human and veterinary practice were determined. The presence of the ermA, blaZ, mecA, and vanA and $B$ genes was also investigated. A population study of the isolated microorganisms was carried out by pulsed-field gel electrophoresis (PFGE).

\section{Material and methods}

$S A$ strains were recovered from cheese made from raw sheep's milk collected 6 hours after molding, a phase generally associated with the highest levels of $S A$. Twelve cheese wheels were collected from six household plants (A-F) located on the island of Sardinia (Italy). Each sample was representative of a different production batch, two from each plant. Samples were analyzed according to UNI EN ISO 6888-2:2004. Thirty-six strains were isolated from typical colonies and identified according to Scarano et al. (2005). For each strain, the MIC was tested by the broth microdilution method (CLSI 2006a, b) for the following antibiotics: ampicillin (AM), cefalotin (CF), cefoperazone (CFP), cloxacillin $(\mathrm{OB})$, erythromycin $(\mathrm{E})$, gentamycin $(\mathrm{GM})$, kanamycin $(\mathrm{K})$, novobiocin $(\mathrm{NV})$, ofloxacin $(\mathrm{OFX})$, oxacillin $(\mathrm{OX})$, penicillin $(\mathrm{P})$, rifampicin $(\mathrm{RA})$, streptomicin $(\mathrm{S})$, tetracycline $(\mathrm{TE})$, tobramycin (TM), and vancomycin (VA). Twelve serial dilutions of each antibiotic were made in cation-adjusted Mueller Hinton Broth (CAMHB; Oxoid LTD Basingstoke, UK) containing $\mathrm{NaCl}(2 \%)$, with the final concentrations of antibiotics ranging from 0.06 to $128 \mu \mathrm{g} / \mathrm{mL}\left(0.006-12.8 \mu \mathrm{g} / \mathrm{mL}\right.$ for RA). The MIC mode, range, $\mathrm{MIC}_{50}$, and $\mathrm{MIC}_{90}$ of the antimicrobial agents were calculated, and antibiotic susceptibility was defined comparing the MICs with reference values (CLSI 2006b). After DNA extraction, multiplex PCR was used (Rosato et al. 2003; Vancraeynest et al. 2004) to detect gyrA encoding the DNA gyrase, agr (I-IV), an accessory gene regulator, blaZ encoding a penicillinase, ermA, a gene encoding resistance to macrolide $\mathrm{E}$, mec $A$ encoding $\mathrm{PBP} 2 \mathrm{a}$, and $v a n A-B$, genes encoding VA resistance. The templates were loaded onto an agarose gel, and electrophoresis was performed. The population study was conducted by PFGE on $S A$ strains according to 
Prevost et al. (1992) after SmaI restriction digest (Invitrogen, CA, USA) of bacterial DNA. Correlations between the isolates were determined by an unweighted pair grouping by mathematical averaging (UPGMA) model with a similarity greater or equal to $80 \%$ of the Pearson correlation coefficient (Gel Compar II, Applied Math).

\section{Results}

Coagulase-positive staphylococci (CPS) in cheese samples ranged from 3.9 to $5.8 \log _{10}$ $\mathrm{CFU} / \mathrm{mL}$. Thirty-six isolates were identified as $S A$ based on their biochemical and metabolic profiles and on the presence of the gyrA gene. All isolates produced TDNase and were coagulase positive. The isolates were characterized by PFGE clusters (P1-P10) and by the presence of $a g r$ and antibiotic resistance genes (Table 1). None of the tested isolates showed resistance to CF, CFP, E, GM, K, NV, OFX, RA, S, and TM. Only two isolates showed intermediate levels of resistance to K (5.6\%), and one to OFX (2.8\%). Four $S A$ strains could not be typed by PFGE. The $S A$ isolates exhibited resistance to AM (36.1\%), $\mathrm{P}(33.3 \%)$, TE $(11.1 \%)$, and $\mathrm{OB}(2.8 \%)$, and the $\mathrm{MIC}_{90}$ for these antibiotics was, respectively, 16.0, 32.0, 64.0, and $32.0 \mu \mathrm{g} / \mathrm{mL}$. $\mathrm{MIC}_{90}$ of the isolates was below the sensitivity range of 13 out of the 16 tested antibiotics. Regarding AM and P resistance, the results of broth microdilution and molecular analysis (i.e., blaZ gene detection) were in agreement, showing a concordance of $94.4 \%$. The only disagreements between results obtained with the two methods applied to an $S A$ blaZ+ isolate that showed resistance only to $\mathrm{AM}$ and one blaZ- isolate with resistance to $\mathrm{AM}, \mathrm{P}$, and $\mathrm{OB}$.

\section{Discussion}

The $S A$ strains isolated during cheese processing were resistant only to AM, P, OB, and TE, which are among the most commonly used antibiotics on dairy sheep farms. In $S A$ isolated

Table 1 Genotypic characterization and antibiotic sensitivity

\begin{tabular}{|c|c|c|c|c|c|c|c|c|c|c|c|c|c|c|}
\hline \multirow[t]{2}{*}{ dairy } & \multirow[t]{2}{*}{ batch } & \multirow[t]{2}{*}{$a g r$} & \multirow[t]{2}{*}{ cluster } & \multicolumn{4}{|l|}{ genes } & \multicolumn{7}{|c|}{ Antibiotics } \\
\hline & & & & mecA & blaZ & $\operatorname{van} A B$ & ermA & AM & $\mathrm{P}$ & $\mathrm{OX}$ & $\mathrm{TE}$ & $\mathrm{E}$ & VA & $\mathrm{OB}$ \\
\hline \multirow[t]{2}{*}{ A } & $\mathrm{L} 1$ & III & $\mathrm{P} 1(4)^{\mathrm{a}}-\mathrm{P} 2(2)$ & - & - & - & - & - & - & - & - & - & - & - \\
\hline & L2 & III & $\mathrm{P} 1(4)^{\mathrm{a}}-\mathrm{P} 2(2)$ & - & - & - & - & - & - & - & - & - & - & - \\
\hline \multirow[t]{2}{*}{ B } & $\mathrm{L} 1$ & IV & P8(3) & - & - & - & - & - & - & - & - & - & - & - \\
\hline & L2 & III & $\mathrm{P} 1(2)-\mathrm{P} 7(1)$ & - & $+(1)$ & - & - & $+(1)$ & $+(1)$ & - & - & - & - & - \\
\hline \multirow[t]{2}{*}{ C } & L1 & I & $\mathrm{nt}^{*}(3)$ & - & - & - & - & - & - & - & $+(3)$ & - & - & - \\
\hline & $\mathrm{L} 2$ & $\mathrm{I}(1)-\mathrm{II}(2)$ & $\mathrm{nt}(1)-\mathrm{P} 9(2)$ & - & - & - & - & - & - & - & $+(1)$ & - & - & - \\
\hline \multirow[t]{2}{*}{ D } & $\mathrm{L} 1$ & II & P3(6) & - & - & - & - & - & - & - & - & - & - & - \\
\hline & L2 & III & P3(6) & - & - & - & - & - & - & - & - & - & - & - \\
\hline \multirow[t]{2}{*}{ E } & $\mathrm{L} 1$ & III & P4(6) & - & $+(3)$ & - & - & $+(3)$ & $+(2)$ & - & - & - & - & - \\
\hline & $\mathrm{L} 2$ & III & $\mathrm{P} 4(6)$ & - & $+(3)$ & - & - & $+(3)$ & $+(3)$ & - & - & - & - & - \\
\hline \multirow[t]{2}{*}{$\mathrm{F}$} & $\mathrm{L} 1$ & $\mathrm{I}(1)-\mathrm{II}(2)$ & $\mathrm{P} 6(1)-\mathrm{P} 10(2)$ & - & $+(2)$ & - & - & $+(3)$ & $+(3)$ & - & - & - & - & $+(1)$ \\
\hline & $\mathrm{L} 2$ & II & $\mathrm{P} 5(1)-\mathrm{P} 10(2)$ & - & $+(3)$ & - & - & $+(3)$ & $+(3)$ & - & - & - & - & - \\
\hline
\end{tabular}

${ }^{*} \mathrm{nt}=$ nontypeable; $+=$ resistant; $-=$ sensitive; ${ }^{\mathrm{a}}=\operatorname{strain} n$ 
from sheep, the agrIII allele is the most frequently observed (De Santis et al. 2005). Fifty percent of the $S A$ strains isolated from four different dairies belonged to the agrIII group, while $27.8 \%$ belonged to the agrII group and were isolated from three dairies $(\mathrm{C}, \mathrm{D}$, and $\mathrm{F}$ ). The strains belonging to the $\operatorname{agrI}$ group (dairies $\mathrm{C}$ and $\mathrm{F}$ ) and to the $\operatorname{agr} I V$ group (dairy $\mathrm{B}$ ) showed low prevalence. A dendrogram showed a specific distribution of isolates from each dairy. Only isolates included in the P1 cluster were observed at two different dairies (A and B). Each of the isolates of the P3, P4, and P10 clusters was recovered at only one dairy (D, $\mathrm{E}$, or $\mathrm{F}$, respectively), but in both production batches. Our results show a good correspondence between PFGE clusters and antibiotic resistance profiles of the isolates. At two dairies (A and D), all the isolates were susceptible to the tested antibiotics. Four strains belonging to the agrI group (dairy C) were untypeable by PFGE and exhibited resistance to TE. In agreement with previous studies on $S A$ strains isolated from raw sheep's milk (De Santis et al. 2005), the mecA gene was not detected in any of the tested strains. The recovery of MRSA strains from half udder milk samples is sporadic and commonly of human origin (De Santis et al. 2005). The agreement between the antibiotic resistance profiles and detection of the corresponding genes was 100\% for E, OX, and VA, and $94.4 \%$ for $\mathrm{AM}$ and $\mathrm{P}$. The determination of the antibiotic resistance profile allowed an understanding of the source of contamination and a trace back to each step of the cheese making process. This study permitted the identification of the spreading of strains with the same profile and their persistence within the cheese plant.

\section{References}

Clinical and Laboratory Standards Institute (2006a) Document M7-A7. Wayne, PA, USA

Clinical and Laboratory Standards Institute (2006b) Document M100-S16. Wayne, PA, USA

De Santis EPL, Mureddu A, Mazzette R, Scarano C, Bes M (2005) Detection of enterotoxin and virulence genes in Staphylococcus aureus strains isolated from sheep with subclinical mastitis. 4th IDF International Mastitis Conference, pp 504-510

European Food Safety Authority (EFSA) (2008) Foodborne antimicrobial resistance as a biological hazard: Scientific Opinion of the Panel on Biological Hazards (Question No EFSA-Q-2007-089)

Moreillon P, Que YA (2004) Infective endocarditis. Lancet 363:139-149

Prevost G, Jaulhac B, Piemont Y (1992) DNA fingerprinting by pulsed-field gel electrophoresis is more effective than ribotyping in distinguishing among methicillin-resistant Staphylococcus aureus isolates. J Clin Microbiol 30:967-973

Rosato AE, Kreiswirth BN, Craig WA, Eisner W, Climo MW, Archer GL, (2003) mecA-blaZ corepressors in clinical Staphylococcus aureus isolates. Antimicrob Agents Chemother 47:1460-1463

Scarano C, Mureddu A, Virdis S, Pilo AL, Mazzette R, De Santis EPL, Bes M (2005) Profilo dei geni che codificano per le enterotossine e la TSST-1 in $S$. aureus isolato da latte di capra alla produzione. Atti LIX SisVet 59:407-408

Vancraeynest D, Hermansa K, Martel A, Vaneechoutte M, Devriese LA, Haesebrouck F (2004) Antimicrobial resistance and resistance genes in Staphylococcus aureus strains from rabbits. Vet Microbiol 101:245-251 